\title{
Making a case for the spiritual significance of Dinkho tsa Badimo as sacred ceramics in museum collections
}

\author{
Ms Mabafokeng Hoeane \\ Tangible Heritage Conservation, School of the Arts \\ University of Pretoria, South Africa \\ Email: u13407547@tuks.co.za \\ Ms Isabelle McGinn \\ Tangible Heritage Conservation and Museum Studies \\ University of Pretoria, South Africa \\ Email: isabelle.mcginn@up.ac.za
}

DOI: https://doi.org/10.46222/pharosjot.102.113

\begin{abstract}
Ceramics as cultural heritage objects have been extensively studied with the main focus being on their functions as vessels used for the transportation, storage, processing and serving of food, and through this study of foodstuffs an exploration of past lifeways, social exchanges and processes. Part of these social processes include beliefs, myths and rituals, particularly those of rulers and chiefs that promote the welfare and wellbeing of a community and assist in social cohesion such as rainmaking. Oftentimes these intangible practices are carried out through tangible conduits such as ceramic vessels, whether to hold potions or mix medicines. Few studies however have focussed their attention on these artefacts, and likewise few have focussed on rituals in domestic settings as used by. In this context, the small ancestral vessel, or Dinkho tsa Badimo, as used by families to engage the ancestors is the focus of the present research. Past museum collection practices could be the cause for this oversight, as these vessels were misidentified, misclassified and incorporated into collections as common household wares, which they resemble. However, highlighting the significance and importance of Dinkho tsa Badimo as a separate class of ceramics, which could be considered 'sacred', requires particular consideration in curatorial practice informed by appropriate cultural protocols. This article, based on interviews with traditional healers and supplemented with published references seeks to underline the importance of the use of ancestral ceramic vessels in the spiritual practices of Sesotho-Setswana cultural groups of Southern Africa.
\end{abstract}

Keywords: Ancestral ceramics, Conservation, Indigenous knowledge systems, Museum collections, Sacred objects.

\section{Introduction}

Religion, spirituality and/or belief plays a number of significant roles in the everyday, providing structure, meaning and understanding, as well as support in difficult times by being a source of strength, comfort and hope and bringing about a sense of community and belonging (Malone \& Dadswell, 2020: [sp]). Typically, rituals and ceremonies are practised to show dedication and faith to a religion, and in the case of the Basotho-Batswana, to show belief in and respect for the ancestors. Belief in the importance of ancestors can be seen as an extension of a belief in, and respect for, elders as guardians and guides for the community (Kopytoff, 1972:131).

Despite Christianity being a dominant religion, most Africans still firmly believe in, and practice, ancestral worship. As Amanze (2003:43) notes "belief in and veneration of ancestors 
continues unabated to the present day... the belief in ancestors in Botswana is based on the fact that it is the core of Tswana Traditional Religion. It gives the people a sense of selfidentity." Ancestral worship can take many forms often facilitated and mediated through the use of tangible objects which link the living community with the spirit world (Alubafi and Kaunda, 2019:1). "In African spirituality, ancestor engagement with the community is always mediated through material objects. Ancestral objects are an embodiment of the ancestors or ancestral meaning-making, which links the visible community to the world of the spirits" (Alubafi and Kaunda, 2019:1). These objects can take various forms from drinking cups to stools (Alubafi and Kaunda, 2019), drums (Lebaka, 2007), and power figures (Kingdon, 2019) amongst others. For the Basotho-Batswana ${ }^{1}$ family homestead, these objects are ceramic vessels referred to as Dinkho tsa Badimo?.

Ceramics can be used for the preparation, cooking and storage of food and beverages. Just as David-Elbiali (1983: 152) describes of the Fon and Gun of South Benin, in Sotho-Tswana groups the vessel's function is inferred in its name. Thus, Nkho ya metsi, is a ceramic vessel used to carry water from the spring and stored for household use, specifically for drinking and cooking; Nkho ya bojwala, stores traditional beer, and Nkho ya dijo stores food. Ceramic vessels used as part of Basotho-Batswana ancestral worship are referred to as Dinkho tsa Badimo, or ancestral vessels. These ceramics come in different shapes, sizes and appearance according to the ritual or ceremony being carried out, such as calling ancestors for assistance and guidance, funerals (Van Schalkwyk, 2016; Opong,1997), and births (Opong,1997). In addition, form and size depends on the offerings they carry including traditional beer, blood from sacrificed animals, cow dung, food and water (Lawton,1967).

Van Schalkwyk (2016:34) notes that Dinkho tsa Badimo also take on a central role in funerals amongst the Basotho in Limpopo, where beer that has been brewed for a funeral is shared amongst the community in the following manner: "Pots full of beer known as tima molato (extinguish the problem) are consumed by family members and in-laws of the deceased, implying that problems that might have risen amongst them are resolved. A second set of pots with beer, referred to as bjalwa bja diphiri (beer of the hyenas) is consumed by the men who dug the grave and is drunk outside the yard. These men are viewed to be ritually impure and as a result have to keep their distance from others until they are ritually cleansed. The third set of pots, are referred to as banyaki ba ditonki are consumed by people who are chance passers-by, for example if they go to look for their donkeys and then decide to join the event." Interestingly, Van Schalkwyk (2016:34) notes that there does not appear to be any distinction of the type of vessel used between the three different groups, the only difference being the size necessary to accommodate the number of guests.

Matsoso (Interview: Semameleng Matsoso, 2020, pers. comm.) explains that traditional beer is offered to the ancestor inside Dinkho tsa Badimo because "In the past, our ancestors didn't have modern cups and plates like we do now. Dinkho were used to serve everything. My grandmother trained me that when elders come and visit your home you serve them traditional beer and $\mathrm{Mageu}^{3}$ as a form of respect." By offering the ancestors the same traditional beer which they drank alive, she believes it pleases them and therefore brings blessings to her life. "Beer is also considered food for the ancestors, and whenever they are to be consulted or

\footnotetext{
${ }^{1}$ The first author has a Basotho-Batswana lineage and found that a common point was the use of Dinho tsa Badimo in ancestral ritual. The Batswana are found mostly in Botswana and the North West province of South Africa, while the Basotho are found in Lesotho and the Orange Free State province of South Africa.

2 The present article focusses on ceramics created by the Basotho-Batswana. 'Nkho' is the SesothoSetswana name for a ceramic vessel, with 'Dinkho' its plural form. Basotho-Batswana refers to the people, while Sesotho-Setswana refers to the languages they speak.
}

${ }^{3}$ Non-alcoholic drink made from sorghum. 
communicated with, beer is offered to them in a special vessel that is only used for sacred ceremonies. Beer is left inside the pot at the ancestral shrine in the courtyard, in other cases, the family would gather in the cattle kraal, where prayers are directed to the relevant ancestor who in all probability is buried there, and the beer is offered" (Van Schalkwyk, 2016: 35).

Apart from the afore-mentioned rituals which extend beyond the family to the community, there are also rituals which call upon the ancestors in a more intimate manner. "Even though they often incorporate traditional beliefs, the religious and worldviews of the Sotho-Tswana are not static but undergo redefinition and transformation in the context of a changing world. SothoTswana-and indeed all African-religious practice has always been open to appropriating new ideas, knowledge, and techniques that seem useful in daily life" (Denbow and Thebe 2006:63). 'Go phatlha' (communicating with the ancestors) is one such ritual which has developed over time, where an African herb known as Helichrysum 'Imphepho'4 is burnt in a small wide open Nkho ya Badimo. Amongst the Zulu imphepho is placed at the bottom part of a clay pot and burnt in order to be able 'to speak to the ancestors'. Smoke from the burning of imphepho was "meant to rise to the ancestors, who convey it to God". (Hutchings 2007: 15). "Eight species of this plant are known to be burnt to invoke the goodwill of ancestors, including two of which may also be used by Zulu diviners to induce trances" (Hutchings, 1996). In the Eastern Cape imphepho is reported to be burnt to clear the air for the ancestors, to safeguard the home against evil spirits during the night and to be used in cleansing rites to purify the body before sleeping (Broster \& Bourn 1982; Hutchings 1986). As adopted in Nguni cultures, the Basotho and Batswana contact their ancestors by burning specific herbs such as imphepho in their Nkho tsa Badimo, with the belief that the scented smoke lifts into the air and awakens the ancestors. "Communications with our ancestors is very important to us. We communicate with them for every major event in our lives from birth to death. We also communicate with them to ask for blessings and protection. The communication is also important in keeping the ancestors happy because when neglected we believe that one can attract bad luck" (Interview: Semameleng Matsoso, 2020, pers. comm.).

In contemporary practice, lit white and red candles can be placed alongside Imphepho to 'kganyisa'5 (light the way), and 'Senefi' ${ }^{6}$ is poured inside the 'Nkho ya Badimo' whilst calling out the names/clan names of the ancestors. 'Go phatlha' is performed for many reasons including prayer, to ask for blessings, guidance and protection from the ancestors as well as on special occasions like the birth of a child, death of a family member, or announcing to the ancestors the arrival of a bride into a new home. It is the heart of African spirituality. During 'Go phatlha', you also offer water, 'Bojwala ba setso' 7 and food in medium sized Dinkho tsa Badimo. The vessels are only used for ancestral ceremonies and nothing else (Interview: Semameleng Matsoso, 2020 pers.comm.). According to Sithole, 'Dinkho tsa Badimo' are always dark or black as they are associated with ancestors. Since it is believed that ancestors visit at night, the pot must be black (Sithole, 2009: 2).

\footnotetext{
${ }^{4}$ Imphepho or mphepo refers to an indigenous flowering plant of the family Helichrysum. The stalks and flowers are widely used as a ritual incense in South African traditional medicine. A survey of plants in umuthi shops in the Johannesburg area by Williams, Balkwill and Witkowski (2001:91) revealed several species are sold as Imphepho including Achyrocline stenoptera 1, st Helichrysum cymosum subsp. calvum 1. st $\mathrm{H}$. decorum 1, st $\mathrm{H}$. epapposum 1, st $\mathrm{H}$. gymnocomum 1, st $\mathrm{H}$. natalitium 1, st $\mathrm{H}$. nudifolium 1, st $\mathrm{H}$. odaratissimum 1, st. The plants have many uses including to induce calm and reduce anxiety, anti-inflammatory, pain-relief, anti-septic, and organic pesticide (Abalimi Bezelkhaya website, 2017: [sp]).

${ }^{5}$ Term can be loosely translated into English as to shine light so that the ancestors can find their way into the room or location.

${ }^{6}$ Traditional homemade snuff (fine crushed tobacco dark brown in color),

${ }^{7}$ Traditional beer made of sorghum.
} 


\section{Dinkho in museum collections}

Artefacts such as Dinkho tsa Badimo, are in general poorly documented in museum collections and can be said to have lost their identity and their connections to the people who considered them sacred/spiritual objects (Seabela, Interview January 30, 2020). During early missionary activity and colonial efforts, local beliefs and traditional ancestor worship were seen as 'dark' and 'heathen' practices; and people from many cultural groups, including the Basotho and Batswana, were encouraged to give up these practices, as well as the objects of ritual and worship connected to them (Thondlana, 2020). Many artefacts such as Dinkho tsa Badimo, masks, power figures, drums etc. were easily separated from their originator communities, collected, looted, deconstructed and dismembered, usually only retaining a portion of the original object for export to the West (Gossiaux, 2007:3). In this way many museums filled their storerooms with African cultural material, including in South Africa. During the 1930's, the South African State reinforced this separation from heritage through the Witchcraft Suppression Act which actively encouraged the confiscation of "articles connected with forbidden practices". In the 1940s the South African Museums Association (SAMA) lobbied for such confiscated objects to be sent to the nearest public museum, instead of being burned by the police as was the practice at the time (Shaw, 1940:58). The exact provenance of many of these artefacts was and still is poorly understood or documented, and many ritual objects which have entered museum collections are misclassified, such Dinkho tsa Badimo which are generally stored alongside other household vessels previously used for the preparation, storage and serving of food. This sadly negates the spiritual dimension of these vessels, and fails to alert museum staff of their sensitive nature as religious wares. In general, museological practice tends to treat all objects according to the same standard procedures, irrespective of the culture from which they originate or their past value and significance to those cultures, particularly if they are not specifically identified as requiring a different set of guidelines. "The items are seen as artifacts, separate from their culture, rather than as cultural links between the past, present and future" (Ogden, 2004: 1). The aim of the article is thus to draw attention to indigenous ceramics in general, suggesting that they could be classified according to function as they are in originator communities, and to encourage the re-identification, redocumentation, and preservation of Dinkho tsa Badimo ${ }^{8}$ as a separate grouping of ceramic vessels, clearly identified and classified as sacred objects. This re-categorization could have important implications for curatorial practice in terms of justification of provenance, research, access, use and handling.

With the increasing calls for transparency in the management of cultural heritage including divulging how institutions came to own the objects and artefacts in their collections, having good records on how objects were acquired is essential. In addition, as institutions seek to become more integrated with and meaningful to their respective communities to remain relevant and sustainable, there is an increased focus in consulting with originator communities to present accurate, respectful and meaningful information. Correct identification and accurate provenance information is thus necessary to locate potential originator communities and identify culturally sensitive and appropriate guidelines. "All cultural ancestral material should be treated with respect no matter to whom it belongs or in what context the object was used. However, sacred or ceremonial materials carry with them additional protocols related to the gender of the handler and daily, seasonal, and annual cycles that dictate when the materials can be handled or stored." (Augustine, 2007: 3).

In order to respect these 'protocols' and preserve the power and agency of ritual objects, it is thus important to consult and collaborate with originator communities to explore, document and understand the tangible and intangible aspects of the object at hand. Co-curation is thus gaining in frequency, relevance, and importance.

\footnotetext{
8 Plural name for ancestral vessels.
} 


\section{Methodology}

In order to assist with the potential re-identification and classification of ceramics such as Dinkho tsa Badimo, a literature survey of published sources on Southern African ceramics was insufficient. Although rituals including some materials and ingredients were well documented, there were few details on how to identify potential ritual ceramics. As such, it was felt that perhaps interviews with traditional healers could shed light on the origin of ritual ceramics, ownership, and an indication of taboos and protocols which exist with regards to their care and handling. The present research was largely based on unstructured interviews with cultural practitioners such as traditional healers in Sotho-Tswana communities, as keepers of indigenous knowledge systems. Acess to participants was limited due to the Covid19 , and so a snowball technique was used, where research participants recruit other participants for a test or study. In total five participants were selected, including four traditional healers, and the custodian of a family Nkho ya Badimo dating back to the 1960s.

Guiding questions were used as a starting point, followed by open-ended questions as the interview progressed. This allowed the interviewees to narrate their experiences with increased freedom and minimal interruptions or redirections. As 'Dinkho tsa Badimo' vessels are personal and have different meaning to different individuals, additional questions were developed as the conversations grew. It was known that the appearance and size of ancestral vessels varied both as a result of fashion and personal choice, but also as form follows function. It was therefore important to understand the various uses of Dinkho tsa Badimo in ancestral worship in order to compile a set of identifying characteristics that could assist in their identification in collections. As such, questions centred on the interviewee's own Dinkho tsa Badimo, its origin, acquisition, age and description of physical characteristics and function.

These interviews formed part of the initial study to understand the commonalities between those that regard these vessels as sacred objects, how and when they are used and cared for. From this data a set of morphological features could be identified to assist in recognising potential Dinkho tsa Badimo. Classification of ceramics can be quite daunting as many different authors develop their own classification systems. Antonites' (2020) classification of ceramics from the archaeological site of Schroda in northern Limpopo was selected, both as the vessel shapes were similar to what was observed in the present research, and because the classification and descriptions were simple and easy to use.

From the available references, interviews, and my own observations, a set of characteristics emerged that could identify possible Dinkho tsa Badimo in collections. These characteristics include thickly potted walls because of the contents they carry including food, traditional beer, water, cow dung, medicine and blood. The vessels are usually dark in colour because of the belief that ancestors like dark colours that resemble the night, as that is when they come out. The vessels are also usually decorated, although there is no apparent standard.

\section{Identifying Dinkho tsa Badimo at the Ditsong National Cultural History Museum (DNCHM)}

DNMCH has a rich selection of Dinkho in the Anthropology collection which dates back to 1898 and is representative of cultural groups in South Africa, including some of Sotho-Tswana origin, the oldest acquired in 1912. These include a great variety of household vessels, storage vessels, drinking containers, as well as ancestral ceramic vessels. The majority of the ceramics were collected by DNMCH researchers over the years (Seabela, interview with author, 2020), with varying levels of accompanying information. As Motsamayi (2019:21) points out, poor documentation and cataloguing is a challenge with many museums in South Africa, where rare objects were often collected as 'curios' and placed in storage with minimal 
accompanying information on provenance, author or originator community, ownership, and local name generally omitted. Motsamayi's (2019:2) experience echoed my own, with a clear distinction in the amount of information noted in the accession registers. When reviewing the period 1930s-1961 during British rule, the registers are written in English and have full detail of where the objects were obtained, the price and sometimes the region where the objects were collected. During the Apartheid years from 1948 to 1994, the information is written in Afrikaans, and less information is recorded than in the prior years, generally only including a vague description, for example "swart Basoetoe pot" (black Basotho pot).

Initially, a survey of the DNMCH accession registers, from 1911 to 1980 was used to identify possible entries of ceramics accessioned as Dinkho tsa Badimo. Only four were specifically labelled Dinkho tsa Badimo, collected between the 1930s and 1960s, all accessioned as donations. This number was too restrictive to contemplate identification characteristics, and was thus supplemented with two additional objects selected based purely on their physical appearance as suggested by data collected in the literature review, and during interviews. In total eight ceramics were documented. From these sources, it was suggested that Dinkho tsa Badimo exhibit the following common physical attributes:

- Vessels are generally small to medium in size $(15 \mathrm{~cm}$ to $30 \mathrm{~cm}$ in height)

- Vessel form varies depending on function and includes incurvate bowls and deep bowls as described by Antonites (2020:255). Some vessels presented mixed characteristics, and so an additional category could be created, a 'recurved bowl' where the mouth diameter measures approximately $2 / 3$ of the height of the vessel. The form of these 'recurved bowls include the neck and opening style of a recurved jar, along with a tapered and rounded base, and a spheroidal body as observed in Antonites' (2020:255) incurvate bowls. However, the body is spheroidal in shape similarly to an incurvate bowl. Some vessels with mixed characteristics which have been identified as a separate category under the term 'recurved bowl' usually have thick walls.

- The vessels are usually dark in colour

- The vessels are usually decorated, with much variation

These characteristics are suggested to assist museum staff in identifying possible Dinkho tsa Badimo within the collection of household wares. As this misclassification negates the spiritual significance of these sacred vessels, and in turn affects possible protocols for access, use and care. it is importance to reassess vessels.

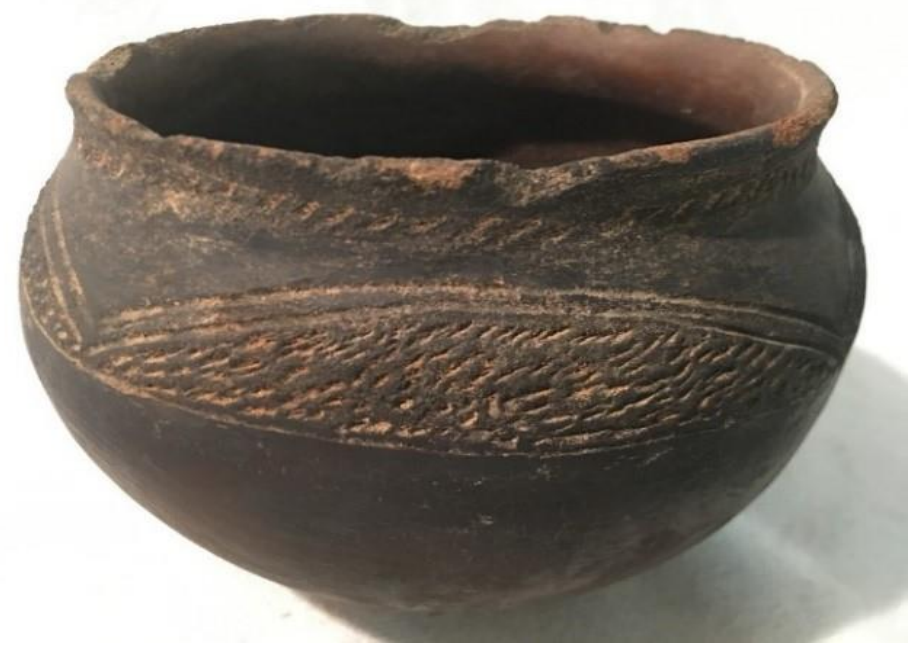

Dinkho tsa Badimo, accessioned 1977, Ditsong National Museum of Cultural History. 


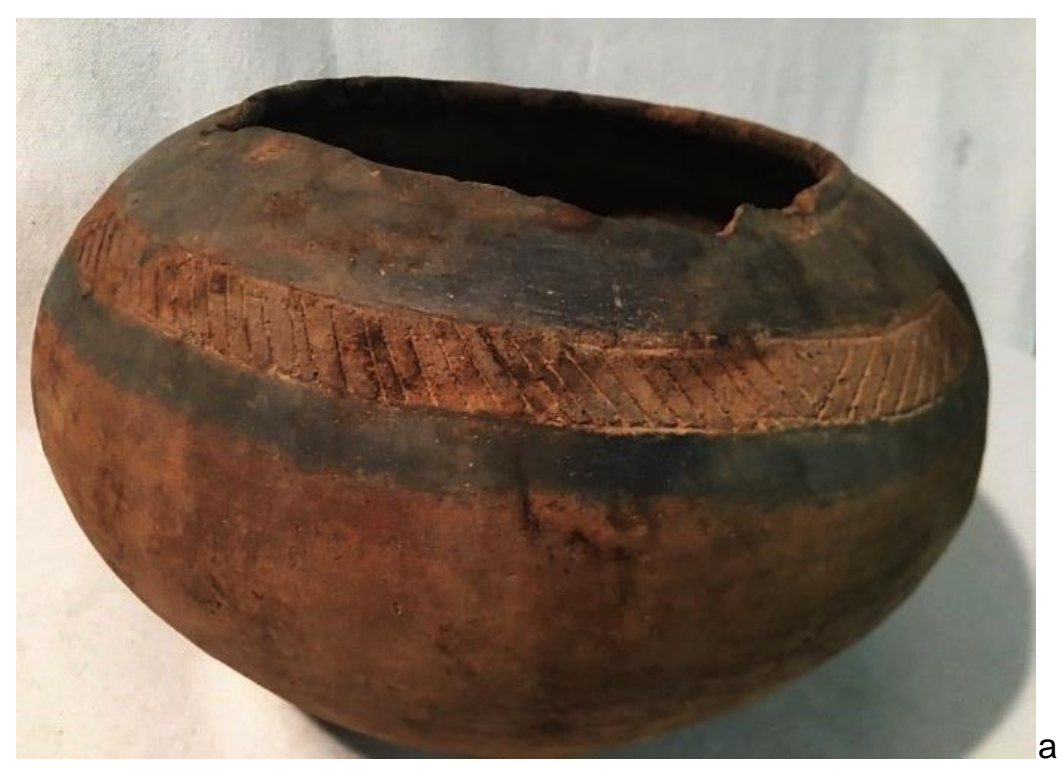

Dinkho tsa Badimo, accessioned 1982 Ditsong National Museum of Cultural History, photograph by Mabafokeng Hoeane.

\section{Using traditional knowledge to inform museum curatorial practice}

An important aspect of the interviews was to understand how practitioners stored and cared for their Dinkho so as to develop culturally appropriate curatorial protocols. Research on culturally appropriate and sensitive curation is an emerging field in many indigenous communities including First Nations in Canada (Clavir, 2002), Alaskan Native people such as the Alutiiq (Haakanson and Steffian, 2004), Native American groups (Ogden, 2004), and Maori (Hakiwai, 2005) amongst others. There is however little available research in this domain within African originator communities to determine what would be deemed culturally appropriate and sensitive curation and conservation of indigenous materials, this is where the present research hopes to contribute.

The interviewees all agreed that that Dinkho tsa Badimo should be separated from household ceramic vessels. Although the same food and beverages are served to the ancestors and the living, those offerings to the ancestors are blessed before serving, and are thus kept separate to avoid contamination (Interview: Tankiso Matsotso, 2020).

Ancestral vessels are stored in cool, out of the way spaces with little to no direct light, such as a corner of the yard, outside the house, under a shady tree or bush. This is also usually the place where damaged or broken vessels are laid to rest (Interview: Tankiso Matsotso, 2020; Interview: Gogo Khanyakude, 2020).

Dinkho are only taken out from their designated storage spot when rituals need to be performed, and only the owner is permitted to retrieve the vessel (Interview: Amanda Khumalo, 2020). In the case of family or heirloom vessels, these are retrieved and handled by the oldest member of the family as a sign of respect (Interview: Semamaleng Matsotso, 2020).

In terms of traditional care, offerings are not allowed to putrefy within Dinkho tsa Badimo. Semamaleng Matsotso describes how the offerings have to be consumed by someone over the age of 65 years. Usually, this will be the same person who is allowed to handle the vessel and its keeper, but in the event this person is younger than 65, the offerings are presented to an elder within the community (Interview: Semamaleng Matsotso, 2020). After every use the 
vessels are cleaned with flowing water to remove residues. Even greasy residues and materials that have dried, such as blood or cow dung are systematically and meticulously removed (Interview: Semamaleng Matsotso, 2020). This concurs with Schapera (1971:50) which recounts how the potsherd used for making medicines is afterwards placed upside down on the hearthstones "to burn all the medicines in it", and the stirring stock is likewise burnt.

Beyond daily care, it is understood and accepted that these vessels have a finite, useable life. When they are broken or damaged and are no longer useable, they are buried in the same space where they would customarily be stored, "to become one with the ancestors and previous owners" (Interview: Semameleng Matsotso, 2020). This attitude and belief could explain why traditional repair is rarely encountered in the literature (Lawton, 1967: 489), despite traditional repair of cultural material having a long tradition on the African continent (Dupré, 2007:29). As objects were not meant to last forever, once the vessel is broken it is replaced with a new one. "When the Nkho ya Badimo I inherited from my grandmother broke, I buried it back home at our family homestead so that it can connect to my ancestors. After this I had a ritual to introduce the new Nkho ya Badimo, this was a special event because I had to sacrifice a goat, so that my ancestors can accept the new Nkho ya Badimo. (Interview: Semameleng Matsoso, 2020, pers.comm.).

Interviews revealed that Dinkho tsa Badimo are not used for other purposes and are treated differently to other household ceramic wares. They are stored in an altogether different part of the household, kept clean and when damaged are ritually discarded. These traditional protocols regarding the care and handling practices surrounding Dinkho tsa Badimo could not be identified in published literature although there are similar practices for other types of ritual objects in Africa. These few customary practices outlined above suggest the basis for culturally sensitive and respectful treatment of Dinkho tsa Badimo that could inform museum practice and provide guidelines for the storage, handling and care of these vessels as sacred objects. Particularly, the acknowledgment of the finite lifespan of Dinkho in their 'living' context raises ethical questions of how these vessels should be treated in an institutional context. For example, if a sacred vessel is accidentally damaged, would it be correct to treat the vessel and repair the damage, or should the vessel be laid to rest, as it would be in a traditional setting?

Questions have been raised regarding the appropriateness of reconstructing deliberately damaged or 'killed' objects, which are ritually broken (Muir, 2007; Butterfield, 2017), a practice found in various African cultures (Smith, 1989; Kankpeyeng et al., 2013). However, there is little literature or guidelines dealing with accidental damage to artefacts in an institutional setting and to what extent these should be restored, if at all.

\section{Recommendations}

Following are a few basic recommendations that would allow a more culturally sensitive and appropriate manner of working with Dinkho tsa Badimo. These recommendations are in no way prescriptive and are merely a suggestion. Most museums already have protocols in place for the access, use and treatment of other culturally significant spiritual or sacred materials. For example, religious manuscripts and African drums are stored in a dedicated area in DNMCH's storage, access is restricted, as is handling and cleaning, which usually only consists of light dusting. In addition, these objects are rarely exhibited, and if they are requested for exhibition, permission is asked from the originator community.

The recommendations suggested are thus based on those existing guidelines which include the following two general recommendations: 
- Currently, the documentation of Dinkho tsa Badimo and other African sacred objects is incomplete at DNCHM and could be an area of research focus to re-examine and identify sacred objects.

- Museums need to engage with source communities on how they expect their sacred objects to be treated in terms of conservation and curation.

In addition, once objects have been identified as Dinkho tsa Badimo, these sacred objects should:

- Be stored along with other sacred objects in DNCHM's storage specifically dedicated to other culturally sensitive and spiritually significant objects.

- If the above is not possible, then Dinkho tsa Badimo should be grouped together on a separate shelf.

- The shelf should be clearly labelled as containing sacred objects to make staff aware that there are potential protocols to be followed when accessing and handling these particular objects.

- Isolating each ceramic in its own custom-made archival box, and clearly labelling the box could also effectively separate the sacred from other household vessels, keep them in the dark and contaminant free. However, this does have resource implications for a collection as large as DNCHM's.

- Although no gender-based cultural restrictions were identified or highlighted in terms of handling Dinkho tsa Badimo, there was reference made to elders being the ones to have access and handle these objects. As such, handling should ideally be done by an older staff member, preferably trained to deal with spiritual objects, or with the assistance of a traditional healer.

- As best museum practice already involves handling objects with clean or gloved hands, this should be observed when handling Dinkho tsa Badimo.

It is important to keep in mind that the above-mentioned guidelines apply only to Dinkho tsa Badimo as ancestral vessels of the Basotho-Batswana and that different cultural groups may have different guidelines to be followed. In addition, guidelines for these ceramic vessels may differ within a cultural group between the types of object under discussion.

\section{Findings and concluding remarks}

Ancestors and ancestral-worship are key to African religious beliefs and the objects and vessels associated with ritual practices are deemed to have strong spiritual significance for their communities. As such, Dinkho tsa Badimo which are central to all rituals associated with ancestors' worship are sacred to the Basotho-Batswana. Past collection and acquisition practices accompanied by incomplete or poor documentation however negates this sacred aspect and many Dinkho tsa Badimo are stored amongst utilitarian household wares.

To rectify this misclassification and correct attribution of function, a series of key morphological features are suggested to identify potential ancestral vessels which warrant further provenance research. In addition a series of culturally sensitive and appropriate curatorial protocols with regards to access, use and care to preserve the intangible qualities of these sacred objects, and not just their materiality is suggested. It is recommended that community engagement is extended beyond the immediate communities that museums serve on a local level, and include originator communities. This would maximise the potential of creating harmony on how sacred objects should be conserved and treated in museums, and additionally create awareness of the role of museums in preserving indigenous knowledge and its associated cultural material. 
With acknowledgement to the South African National Institute of the Humanities and the Social Sciences (NIHSS) for financially supporting the research presented in this special edition. (Project CRP20-1032: African Oral art in image-text objects: Cultural translations of precolonial memories and remains)

\section{References}

Alubafi, M. F. \& Kaunda, C. J. (2019). 'Embodied ancestors: Religious objects, moral actions and well-being in the Cameroon Western Grassfields', Hervormde Teologiese Studies, 75(1), $1-8$.

Amanze, J. N. (2003). 'Christianity and ancestor veneration in Botswana', Studies in World Christianity,9 (1), 43-59. Available online at

http://search.ebscohost.com.uplib.idm.oclc.org/login.aspx?direct=true\&db=rfh\&AN=ATLA000 1540000\&site=ehost-live\&scope=site (Accessed: 7 October 2020).

Antonites, A. (2020). Cooking, Serving, and Storage: Ceramic Vessel Function and Use Contexts at Schroda. African Archaeological Review, 37(2), 251-270.

Augustine, S. (2007). Indigenous Knowledge and Traditional Knowledge, Department of Anthropology, University of Pennsylvania.

Broster, J. A. \& Bourn, H.C. (1982). Amagqirha. Cape Town: Via Afrika.

Bronitsky, G. (1986). The use of materials science techniques in the study of pottery construction and use. Advances in Archaeological Method and Theory, 9, 209-276.

Butterfield, V. (2017). Broken: Consolidating Killed Objects and Conservation. Unpublished Masters Thesis. University College London.

Buys, S \& Oakley, V. (1993). Conservation and Restoration of Ceramics. Routledge. Oxford, England.

Clavir, M. (2002). Preserving what is valued: Museums, conservation and First Nations. Vancouver: UBC Press.

David-Elbiali, M. (1983). Poterie domestique et rituelle du Sud-Bénin: étude ethnoarchéologique. Archives suisses d'anthropologie générale, 47(2), 121-184. Available online at http://archive-ouverte.unige.ch:24376 (Retrieved January 10, 2020).

Denbow, J. \& Thebe, P. (2006). Culture and customs of Botswana in Culture and Customs of Africa. Greenwood Press. Connecticut, United States of America.

Delius, P. (2001). Witches and Missionaries in Nineteenth Century Transvaal. Journal of Southern African Studies, 27(3), 429-443. Available online at https://www.jstor.org/stable/823309 (Retrieved April 22, 2020).

Dupré, M.C. (2007). La réparation en Afrique: un moment de la vie des objects. In: Objects Blessés: la réparation en Afrique. Gaetano Speranza (ed) Musée de Quai Branly, Paris.

Gossiaux, P. (2007). Conserver, restaurer: écrire le temps en Afrique. Available online at http://journals.openedition.org/ceroart/253. (Retrieved January 25, 2021). 
Hakiwai, Al. (2005). The search for legitimacy, Museums in Aotearoa, New Zealand - a Maori viewpoint. In: Gerard Corsane (ed) Heritage, Museums and Galleries: an introductory reader, 154-162.

Hutchings, A. \& Johnson, C. (1986). Glimpses of a Xhosa Herbal. Veld and Flora, 72, 59-62.

Hutchings, A. (1989). Some Observations on Plant Usage in Xhosa and Zulu Medicine. Bothalia 19(2), 225-235.

Hutchings, A., Scott, A.H., Lewis, G. \& Cunningham, A. (1996). Zulu Medicinal Plants- An Inventory. Pietermaritzburg: University of Natal Press.

Kankpeyeng, B., Swanepoel, N., Insoll, T., Nkumbaan, S., Amartey, S. \& Saako, M. (2013). Insights into Past Ritual Practice at Yikpabongo, Northern Region, Ghana. The African Archaeological Review, December 2013, 30 (4), 475-499. Available online at https://www.jstor.org/stable/42641841 (Retrieved January 10, 2021).

Kopytoff, I. (1972). Ancestors as Elders in Africa. Africa, 41(2), 129-142. Available from: https://www.jstor/stable/1159423 (Retrieved 10 October 2020)

Lebaka, M.E.K. (2014). 'Music, singing and dancing in relation to the use of the harp and the ram's horn or shofar in the Bible: What do we know about this?', HTS Teologiese Studies/TheologicalStudies, 70(3).

Lawton, A.C. (1967). Bantu Pottery of Southern Africa, Annals of the South African Museum.

Malone, J. \& Dadswell, A. (2018). The Role of Religion, Spirituality and/or Belief in Positive Ageing for Older Adults. Geriatrics, 3(2), 28. https://doi.org/10.3390/geriatrics3020028 (Retrieved October 22, 2020).

Muir, K. (2007). Wounded Masterpieces: Restoring works of art when damage carries meaning. Unpublished PhD Thesis, Queen's University, Kingston, Ontario.

Ogden, S. (2004). Cultural Considerations of Preservation. In: Caring for American Indian Objects: a practical and cultural guide. St Paul: Minnesota Historical Society Press.

Shaw, E.M. (1940). Letter to SAMA regarding articles confiscated from Natives. SAMAB 3(2), 58.

Smith, F.T. (1989). Earth, Vessels, and Harmony among the Gurensi. African Arts, 22(2), 6065, 103. https://www.jstor.org/stable/3336719 (Retrieved January 10, 2021).

Thondhlana, T.P. (2015). Old wine in new bottles: a critical historiographical survey of Zimbabwean museum institutions. In: African Museums in the Making: Reflections on the Politics of Material and Public Culture in Zimbabwe.

Van Schalkwyk, J.A. (2016). Dipitsa ke Bophelo: Pottery from the Collection of Ditsong: National Museum of Cultural History, Pretoria. Fishwicks, Pretoria

Willoughby, W.C. (1928). The soul of the bantu. London: SCM.77 